\title{
KEHIDUPAN SURAU DI MINANGKABAU SEBAGAI INSPIRASI DALAM KARYA SENI LUKIS
}

\author{
Ferdian Ondira Asa ${ }^{1 *}$, Sahrul. $\mathbf{N}^{2 *}$ \\ Minat Penciptaan Seni Rupa Program Pascasarjana \\ Institut Seni Indonesia Padang Panjang \\ Jl. Bahder Johan, Guguak Malintang, Padangpanjang, Kota Padangpanjang, 27126. \\ Sumatera Barat. Indonesia. \\ Email:asa.04r@gmail.com
}

\begin{abstract}
Abstrak
Surau di Minangkabau sebagai tempat ibadah lebih dikenal sebagai mesjid, langgar dan musalla. Kehidupan surau sebagai tempat pendidikan anak anak pada saat dahulu mendidik anak laki-laki di surau sebagai tempat bermalam, bermain, menggaji. Model pendidikan ini sudah merubah fungsi sebagai pendidikan modern. Fenomena surau masa lalu sebagai konsep dalam bekarya seni lukis, kehidupan surau di Minangkabau sebagai inspirasi dalam karya seni lukis merupakan bagian dari restrospeksi terhadap realita saat ini. Metode penciptaan karya seni lukis melalui riset etik dan riset emik. Riset etik melalui teknik observasi, wawancara, mengamati dan mendokumentasikan fenomena yang ada di kehidupan surau. Riset emik teknik melukis membuat model dengan menggunakan plastisin untuk objek-objek utama kemudian di potret dengan kamera foto. Potret di jadikan sebagai acuan dalam melukis. Karya seni lukis yang divisualkan pada lukisan realis fotografi yang menceritakan kehidupan surau masa lalu, kehidupan tersebut seperti pendidikan, lukisan mengaji, batapian, bujang surau. Karya seni lukis tersebut bermaksud memberitahukan serta mengajak masyarakat untuk menghidupkan kembali kehidupan di surau. Sebab, kegiatan yang dilakukan di surau tersebut dapat membentuk karakter pemuda-pemudi di Minangkabau menjadi lebih baik. Ekspresi yang hadir dalam penciptaan karya merupakan perasaan marah, kecawa dan sedih, melihat fenomena yang terjadi. Kemudian diterapkan ke dalam karya seni lukis berbentuk dua dimensi, berupa simbol. Simbol yang hadir metafhor dari bentuk surau kemudian didisformasikan, sehingga hadir bentuk baru yang mewakili dari visual peranan kehidupan surau Minangkabau, dengan berpedoman pada unsur-unsur seni rupa.
\end{abstract}

Kata Kunci: surau, restrospeksi, fenomena budaya, Minangkabau

\begin{abstract}
Surau in Minangkabau as a place of worship is better known as mosques, langgar and musalla. The life of surau as a place for children's education when they first educated boys in surau as a place to spend the night, play, pay. This educational model has changed the function of modern education. The past surau phenomenon as a concept in the work of painting, the life of surau in Minangkabau as inspiration in painting is part of the retrospect of the current reality. Methods of creating paintings through ethical research and emic research. Ethical research through observation, interview techniques, observing and documenting phenomena that exist in surau life. Emik research painting techniques make models using plasticine for the main objects and then portrayed with a photo camera. Portrait is used as a reference in painting. The visualized artworks in realist photography that tell the life of the past, life such as education, mangaji painting, bujang surau. The artwork aims to inform and invite people to revive life in surau. Because, the activities carried out in the surau can shape the character of young people in Minangkabau to be better.Expressions that are present in the creation of works are feelings of anger, laughter and sadness, seeing the phenomena that occur. Then it is applied to two-dimensional painting, in the form of symbols. The symbol that metaphor comes from the surau form is then informed, so that there is a new form representing the visual role of the life of the Minangkabau surau, guided by the elements of art.
\end{abstract}

Keywords: surau, restrospect, cultural phenomenon, Minangkabau

\section{PENDAHULUAN}

Penciptaan karya seni lukis kehidupan surau di Minangkabau sebagai inspirasi adalah karya seni lukis dengan konsep garap karya modern melalui ide tradisi.
Karya seni lukis ini tergolong ke dalam karya realisme fotografi. Dikaitkan dengan keberadaan dan kekuatan untuk menyamai hasil fotografi yang sangat detail dalam menangkap objek. Penciptaan karya seni lukis 


\author{
Gorga Jurnal Seni Rupa \\ Volume 07 Nomor 02 \\ p-ISSN: 2301-5942 | e-ISSN: 2580-2380
}

kehidupan surau di Minangkabau sebagai inspirasi berasal dari tema renungan pengkarya terhadap restrospeksi surau. Pemikiran tersebut berawal dari rasa peduli pengkarya terhadap merosotnya moral dan akhlak masyarakat Minangkabau di zaman sekarang. Seperti, tidak peduli terhadap sesama, emosional, dan tidak memiliki mental yang kuat. Hal tersebut merupakan dampak dari memudarnya bahkan hilangnya kehidupan masyarakat di surau, khususnya di Minangkabau.

Surau memiliki peran penting untuk membentuk karakter masyarakat Minangkabau. Surau adalah kepunyaan kaum, surau didirikan sebagai pelengkap Rumah Gadang yang berfungsi sebagai tempat bertemu, berkumpul, dan tempat tidur laki-laki yang telah akil baligh serta orang tua yang telah uzur (Azra, 2017:17). Fungsi ini berkaitan erat dengan ketentuan adat bahwa anak laki-laki tidak mempunyai kamar di Rumah Gadang, di rumah orang tuanya sendiri. Setelah masuknya Islam, surau mengalami proses islamisasi walaupun tetap menjadi penginapan anakanak bujang. Jadi, keberadaan surau adalah sebagai tempat berkumpulnya pemuda-pemudi Minangkabau, khususnya anak laki-laki dan sebagai lembaga bagi setiap masyarakat (anak laki-laki) di Minangkabau untuk menerima pendidikan keagamaan lebih awal.

Surau yang merupakan sistem pendidikan tradisional di Minangkabau dapat melahirkan generasi-generasi berakhlak mulia, berkarakter, dan memiliki pemahaman agama yang kuat. Melalui pendidikan di surau, anak laki-laki Minangkabau mampu menjadi pribadi yang kuat. Namun, hal tersebut dapat memudar dikarenakan adanya urbanisasi. Urbanisasi sangat memungkinkan memperlemah hubungan kekerabatan di Minangkabau (Azra, 2017:92). Akibatnya, fungsi surau sebagai lembaga pendidikan Islam mulai terabaikan, terutama oleh keluarga yang berada di pusat-pusat kota.

Secara umum, antara surau dengan masjid memiliki fungsi yang sama, yaitu tempat beribadah. Namun, secara khususnya, antara keduanya memiliki perbedaan fungsi. Pada mulanya, masjid dalam masyarakat Minangkabau hanya dipergunakan untuk shalat Jumat, sedangkan untuk kegiatan keagamaan lainnya dipusatkan di surau. Sementara itu, di surau tidak dilakukan kegiatan shalat Jumat. Gazalba (1989:9) mengatakan, "Kata surau merupakan istilah Melayu - Indonesia. Kata tersebut banyak digunakan di Minangkabau, Sumatera Selatan, Semenanjung Malaysia, Sumatera Tengah, dan Patani (Thailand). Surau merupakan peninggalan kebudayaan masyarakat Minangkabau sebelum datangnya Islam”. Berbeda dengan masjid, masjid berkembang menjadi pusat pengajaran dan pembelajaran Alquran, sementara surau-surau yang masih ada hingga kini banyak yang tidak aktif lagi. Minimnya kegiatan di surau menyebabkan surau tidak terurus dan tidak terkelola dengan baik. Pada akhirnya, surau menjadi bangunan tua yang tidak berfungsi lagi.

Sebutan surau dikonotasikan dengan istilah langgar atau mushalla. Meskipun secara substantif tidak sepenuhnya disamakan begitu saja. Surau muncul jauh sebelum langgar atau mushalla berdiri. Istilah surau merupakan warisan dari agama Hindu-Budha atau para leluhur mereka yang menganut animisme, dinamisme, ataupun politeisme. Langgar biasanya digunakan untuk shalat dan mengaji bagi kaum Muslim di Jawa. Kemudian, para jamaah melanjutkan dengan membaca Alquran bersama yang dipimpin oleh seorang imam yang ditunjuk sebagai pendidik. Istilah mushalla merupakan pengembangan mutakhir

Penciptaan karya seni lukis kehidupan surau di Minangkabau sebagai inspirasi berasal dari pendidikan Islam di Minangkabau. Oleh sebab itu, surau menjadi bentuk dalam konsep penciptaan dan mengungkapkan rasa dalam berkarya melalui interpretasi. Kehidupan surau yang dijadikan karya lukis adalah alang-alang dan mangaji.

\section{KAJIAN TEORI}

Setiap karya seni membutuhkan penafsiran yang tepat untuk menghasilkan penilaian yang baik. Penafsiran tersebut berasal dari gagasan yang menjadi sebuah ekspresi personal sebagai konsep penciptaan dalam berkarya. Tugas pelukis adalah memproduksi hal yang berdimensi tiga ke dalam suatu bidang datar (kanvas). Ruang dan isi tidak dapat dipisahkan, tidak ingin sekedar meniru alam (mimesis), melainkan alam ini di ciptakan kembali untuk memperoleh bentuk-bentuk yang kuat (Myers dalam Dharsono, 2016:131).

Seni lukis merupakan salah satu dari sekian banyak media untuk mengungkapkan ekspresi seseorang. Konsep penyusunan menggunakan idiom tradisi sebagai wadah ekspresi dengan jalan meminjam sebagian bahasa metafora dalam garap seni secara ekspresi simbolik menggunakan teknik deformasi. Deformasi adalah penggambaran bentuk pada pencapaian karakter dengan menggambarakan bagian objek dianggap mewakili. Sementara media-media yang digunakan adalah kanvas dalam karya seni rupa, yaitu seni lukis. yang masih sangat baru. 


\section{Gorga Jurnal Seni Rupa \\ Volume 07 Nomor 02 \\ p-ISSN: 2301-5942 | e-ISSN: 2580-2380}

Berdasarkan proses observasi dan interpretasi penulis terhadap objek, penulis menemukan beberapa bentuk karya-karya yang akan menjadi referensi. Melalui referensi tersebut akan tampak perbedaan dari segi bentuk maupun dalam penggunaan objek yang memiliki unsur nilai budaya adat Minangkabau. Karya -karya tersebut meliputi:

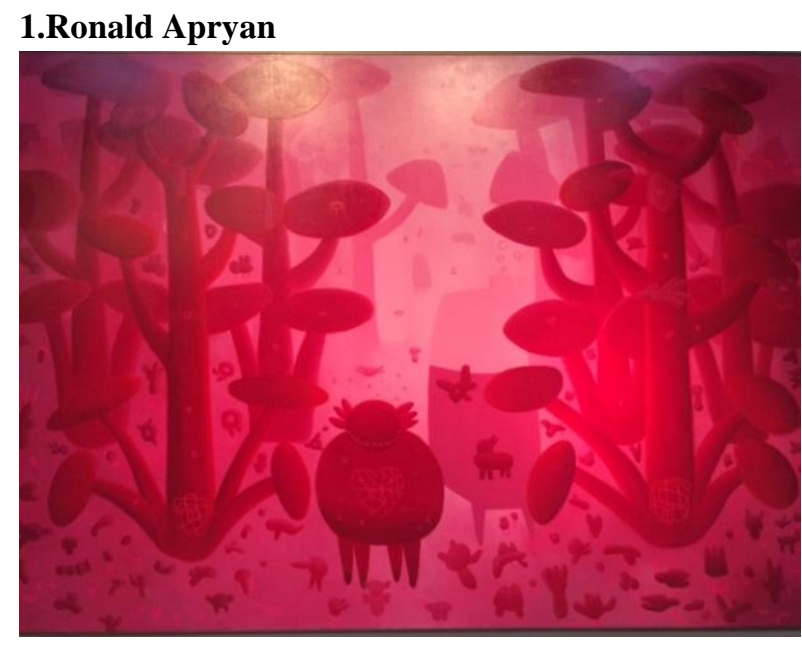

Gambar 1.

Lukisan Ronald Apryan, judul: Persembahan Cinta, $180 \mathrm{~cm}$ x 250 cm acrylic on canvas 2017

(http://www.harpersbazaar.co.id/articles/read/2/2017/3471/Persemb ahan-Cinta-Seorang-Ronald-Apriyan, Ferdian Ondira Asa, 20/042018)

Salah satu karya Ronald dalam pameran tunggalnya di bentara budaya Jakarta yang bertajuk persembahan cinta. Beberapa karyanya merupakan persembahan bagi hal hal sentimental dalam dirinya. Konsep karya Ronald ini "Di Tengah Gesekan dan Konflik yang Banyak Terjadi saat Ini, cinta adalah hal yang bisa menjadi obat bagi itu semua," Seperti hutan di dekat tempat tinggalnya ketika masa kanakkanak, impiannya memiliki rumah pribadi, gejolak memilih pemimpin, hingga wujud kecintaannya terhadap dunia seni lukis, seperti yang digoreskannya dalam lukisan berjudul Persembahan Cinta. Ronald menggunakan teknik garap surrealisme, dan menghadirkan nuansa warna warna cerah yang monokrom. Hal ini memiliki kesamaan dengan karya yang akan diciptakan seperti warna yang cerah dan monokrom. Namun, memilki perbedaan seperti bentuk visual yang nantinya banyak memakai idiom tradisi sebagai penyusunannya.

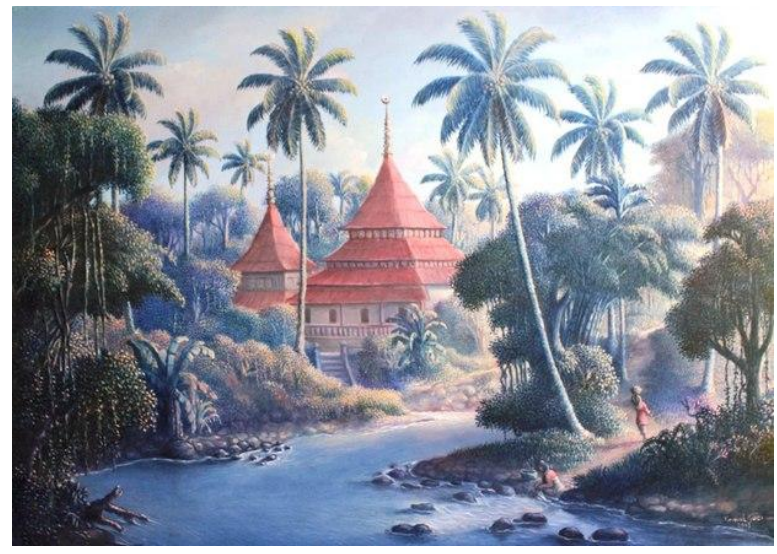

Gambar 2.

Kamal Guci, 2013, Tapian, 140 x 100, oil on kanvas Sumber katalok pameran tunggal Kamal Guci bertema "Retrospeksi"

Kamal Guci melukiskan alam sebagai refleksi sosial agar kita kuasa untuk kembali meredefinisi perubahan kultural, sehingga terbentuk keseimbangan dalam alam pikir, batin dan tindakan sehari-hari. Kamal Guci membaca, meresapi, menghayati, mengenang kembali pengalaman perjalanan hidupnya sebagai retrospeksi diri, keluarga, masyarakat dan lingkungannya. Kamal Guci adalah seorang perupa yang lahir di sarang gagak Nagari Pakandangan kecamatan anam lingkung pada 13 Oktober 1960, dan melalui proses kreatifnya sebagai perupa di Tanah Minang, Sumatera Barat.

\section{Ipan M. Irfan}

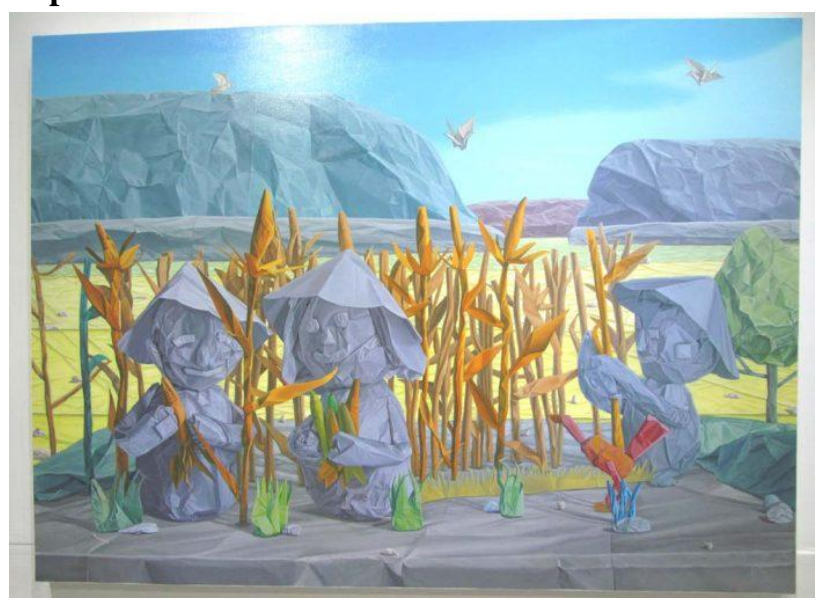

Gambar 3

Foto; Lukisan Ipan, M. Irfan. Judul: Industri Tanah, acryllic on linen, $110 \times 150 \mathrm{~cm}, 2017$

Foto: A. Sartono(https://www.tembi.net/2017/06/03/squezee-landcitra-kertas-remas-dalam-karya-lukis-ipan/, Ferdian Ondira Asa, 20/042018)

Berdasarkan karya tersebut, Ipan memulai penjelajahan imajinasi atas ide-ide yang ada di dalam dirinya. Ingatannya akan masa kecilnya di

\section{Kamal Guci}




\section{Gorga Jurnal Seni Rupa \\ Volume 07 Nomor 02 \\ p-ISSN: 2301-5942 | e-ISSN: 2580-2380}

Ranah Minang, banyak memberikan kontribusi atas karya-karyanya. Ingatannya akan kebiasaan berkebun atau bertani bagi sebagian orang Sumatera Barat misalnya, menjadi pengalaman batin yang terus dikenang dan direkam dalam ingatan dan diwujudkannya kembali dalam karya seni.

Berangkat dari itu tentu ada proses estetisasi atas subyek karyanya yang menjadikan karya garapannya tidak sekadar melakukan praktik "ars imitator naturam" (seni itu memindahkan alam). Dengan demikian, memandang karya-karya Ipan seperti memandang seniman yang sedang melakukan reimajinasi atas masa lalunya. Dalam perwujudan karya lukis ini, Ipan menggunakan teknik garap surrealisme. Hal menarik lainnya dari karya karya ipan ini adalah dengan selalu membuat model untuk karya lukisnya. Dengan teliti, telaten, dan tekun ia meremas-remas kertas (terutama HVS putih ukuran kuarto) sambil pelan-pelan membuat bentuk terhadap kertas yang diremas tersebut dengan bantuan perekat. Hasil bentukan atas kertas yang diremas tersebut bisa bercitra manusia, flora, fauna, kendaraan, dan sekian bentuk benda lainnya.

Berdasarkan review karya Ipan dan Ronald dengan karya penulis, diketahui memiliki kesamaan ide-ide dan konsep. Kesamaan berikut sama-sama menggunakan konsep ekspresi simbolik namun berbeda idiom yang dipinjam. Penulis mengambil idiom tradisi dari surau sedangkan Ipan banyak memakai idiom Minangkabau.

\section{METODE PENELITIAN}

Persoalan mendasar dalam penciptaan ini adalah bagaimana mengeksplor ide-ide tentang kehidupan surau dengan gaya realis. Hal ini terkait pengembangan informasi dengan cara menganalisis secara teliti dan rinci tentang data-data yang diperoleh serta teori atau paham tentang karya seni lukis yang berkaitan dengan tema yang akan diwujudkan. Metode penciptaan dilakukan melalui dua langkah yaitu riset emik dan etik.

\section{Riset Emik}

\section{1). Observasi Langsung}

Dengan mendatangi langsung surau Syekh Burhanuddin. Observasi selanjutnya, mendatangi Kamal Guci. Kamal Guci adalah seorang seniman yang banyak melahirkan karya dari alam sebagai refleksi sosial agar kita kuasa untuk kembali meredefinisi perubahan kultural, sehingga terbentuk keseimbangan dalam alam pikir, batin dan tindakan sehari-hari. Seniman ini sedikit banyak mengetahui fenomena kehidupan di surau. Kamal Guci melewati proses membaca, meresapi, menghayati, mengenang kembali pengalaman perjalanan hidupnya sebagai retrospeksi diri, keluarga, masyarakat dan lingkungannya. Kamal Guci adalah seorang perupa yang lahir di Sarang Gagak Nagari Pakandangan Kecamatan Enam Lingkung pada 13 Oktober 1960.

Setelah berada ditempat observasi tersebut, setiap data mengenai surau berupa foto artefak diabadikan dengan mendokumentasikan secara pribadi.

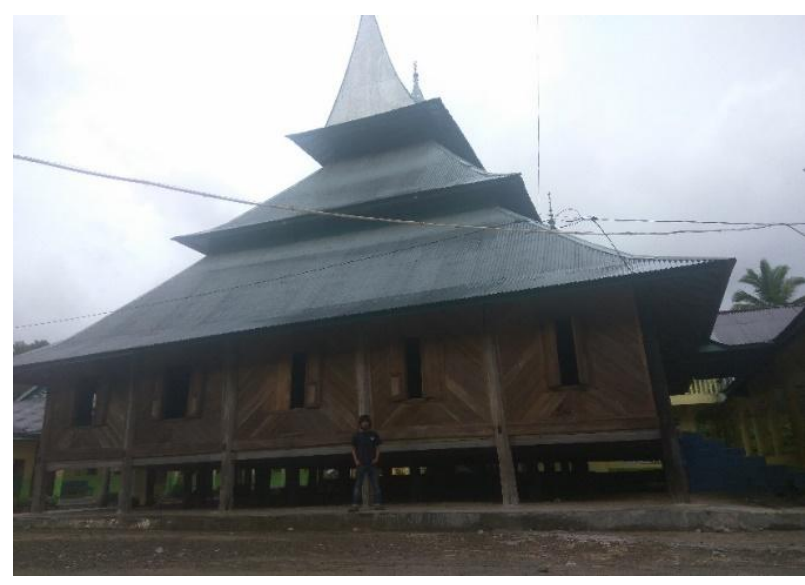

Gambar 4.

Foto; Surau Syekh Burhanuddin

(Dokumentasi pribadi: Asa, 2017)

Surau Syekh Burhanuddin terletak di desa Tanjung Medan, $6 \mathrm{~km}$ dari makam Ulakan. Lokasi surau agak masuk ke dalam dari jalan raya. Surau terletak di atas tanah yang datar dengan halaman yang luas. Bahan bangunan surau Syekh Burhanuddin seluruhnya dari kayu, baik tiang maupun konstruksi atap dan dinding. Atapnya dulu terdiri dari ijuk yang kemudian diganti dengan atap seng pada tahun 1920.

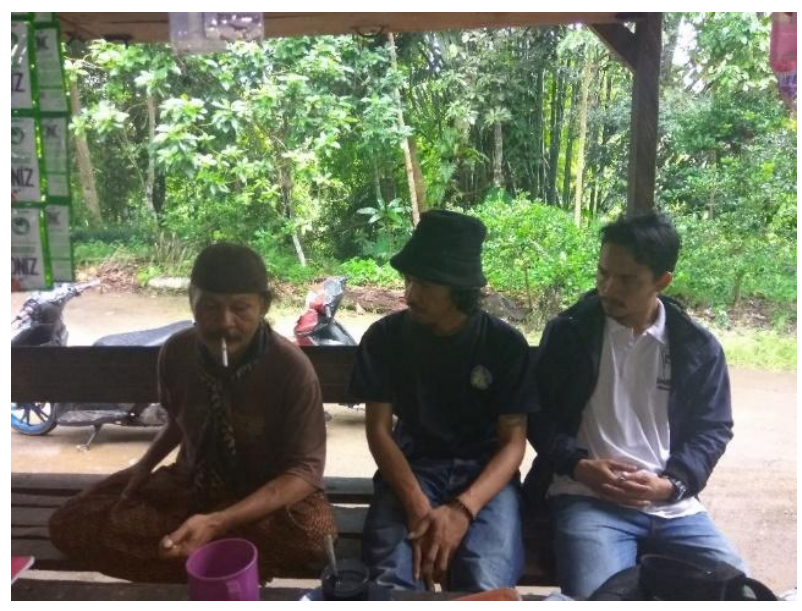

Gambar 5.

Foto, wawancara dengan seniman Kamal Guci (Dokumtasi pribadi Asa, 2017)

\section{2).Dokumentasi}




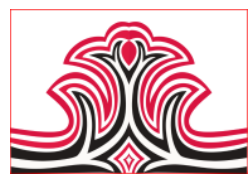

Bapak Kamal Guci, seorang seniman yang sudah banyak mewujudkan karya seni lukisnya dengan mengunakan idiom tradisi Minangkabau, dari beberapa karyanya berawal dari ide cipta tentang kehidupan surau Minangkababau, beliau juga anak surau, bujang surau bahkan sekarang bisa di katakana bapak surau.

\section{Riset Etik}

Mempelajari karya-karya ilmiah berupa buku, jurnal, dan artikel terkait dengan surau dan budaya Minangkabau. Khususnya, tentang fenomena kehidupan di surau. Dari hasil mempelajari, timbullah ide cipta penulis terhadap kehidupan surau Minangkabau dengan beberapa gambar yang jadi acuan dalam penciptaan karya seni lukis realis fotografi.

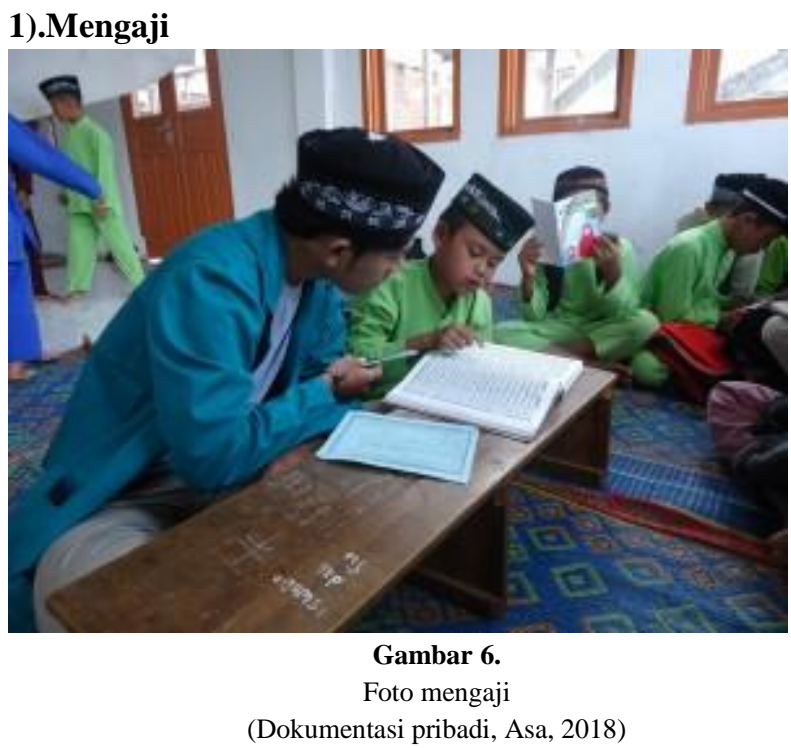

Mengaji di gunakan sebagai gambar acuan pada karya seni lukis melalui dua pertimbangan, pertama sebagai salah satu manfaat dari kehidupan surau Minangkabau, pertimbangan kedua pencahayaan mengunakan lampu petromak sehingga memberi anologi tentang zaman dahulu yang belum ada listrik seperti sekarang ini, pertimbang tersebut berasal dari kehidupan surau Minangkabau.

\section{2).Tidur di Mesjid}

Gorga Jurnal Seni Rupa

Volume 07 Nomor 02 p-ISSN: 2301-5942 | e-ISSN: 2580-2380

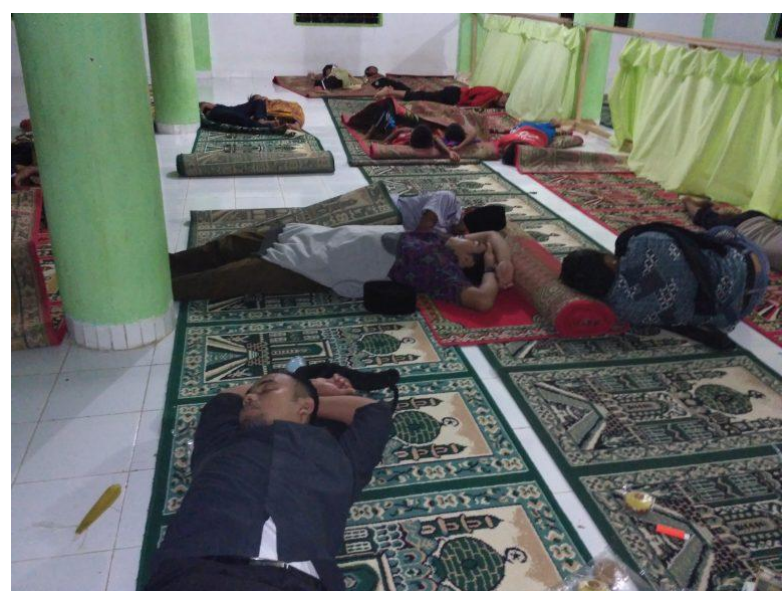

Gambar 7.

Foto, Tidur di mesjid

(Dokumtasi pribadi, Ridwan, 2017)

Tidur beralasan tikar Mesjid bisa pules apalagi disaat mata mengantuk dan badan teramat letih. Inilah yang terjadi malam tadi di Masjid Baitul Rahim, Kampung Teluk Kasai, Kecamatan Batang Kapas, Kabupaten Pesisir Selatan, Sumatera Barat. Anggota FSRBK (Forum Silaturahmi Rang Batang Kapeh) tidur berhamparan bersama pemuda dan anak anak di mesjid itu.Tidur bergelimpangan dan berhamparan di masjid atau di surau surau ini dulu bagi anak anak muda dizaman kecil dulu ini termasuk sebuah tradisi.

\section{Eksperimen \\ 1).Cat Akrikilik}

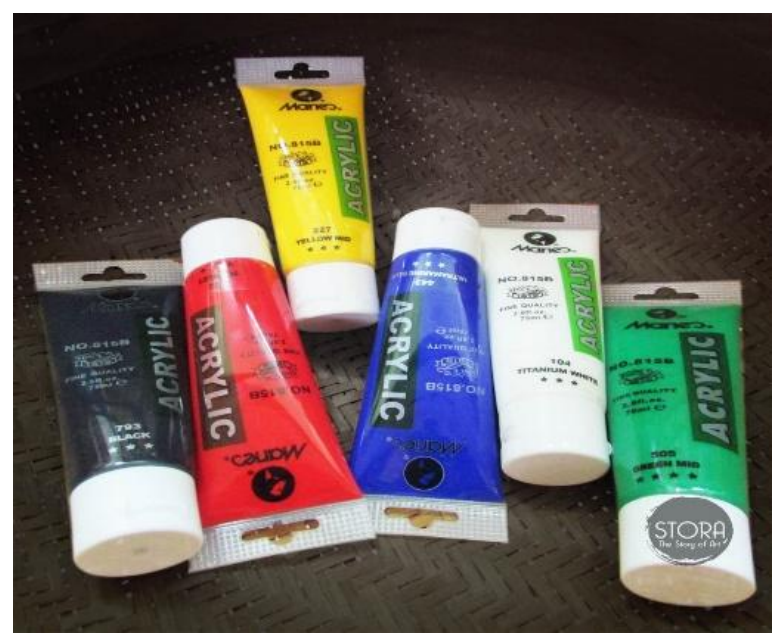

Gambar 8.

Foto Cat Akrilik

(foto: Asa, 2018)

Penguasaan bahan dilakukan menggunakan cat akrilik. Cat akrilik merupakan bahan melukis yang memakai pelarut air, digunakan di atas pertimbangan kecerahan warna yang dihasilkan serta sifat cat yang mudah kering membantu proses kreativitas lebih efektif menghemat waktu. Pengkarya memperlakukan cat akrilik seperti cat air pada umumnya, termasuk 


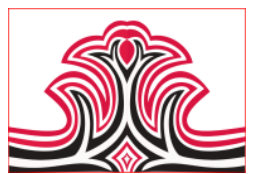

mencampurnya dengan air secukupnya. Semakin banyak air maka cat akan semakin encer dan hasil sapuan kuas akan terlihat terang atau menimbulkan kesan "transparan". Hanya, berbeda dengan cat air yang tidak tahan lama, cat akrilik kering permanen. Perpaduan teknik dry brush dan washing tentu akan lebih manjur untuk menciptakan varian tekstur di atas selembar permukaan kain. Berikut hasil eksperimen cat akrilik pada kertas:

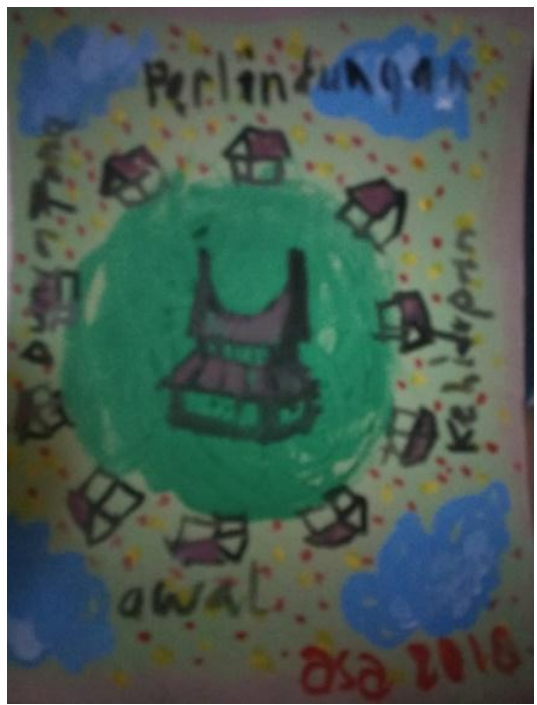

Gambar 9.

Foto Hasil eksperimen cat akrilik pada kertas (foto: Asa, 2018)

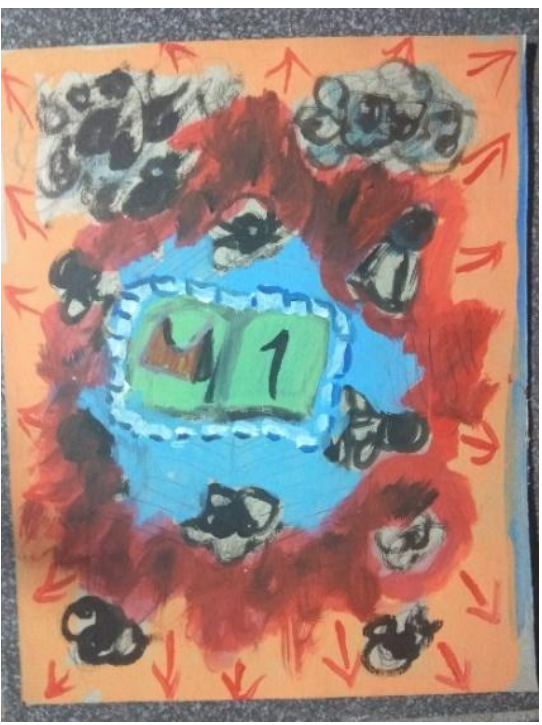

Gambar 10.

Foto Hasil eksperimen cat akrilik pada kertas (foto: Asa, 2018)

Hasil eksperimen dari cat akrilik ini memberi ide cipta terhadap penciptaan karya seni lukis kehidupan surau Minangkabau sebagai inspirasi.
Gorga Jurnal Seni Rupa

Volume 07 Nomor 02

p-ISSN: 2301-5942 | e-ISSN: 2580-2380

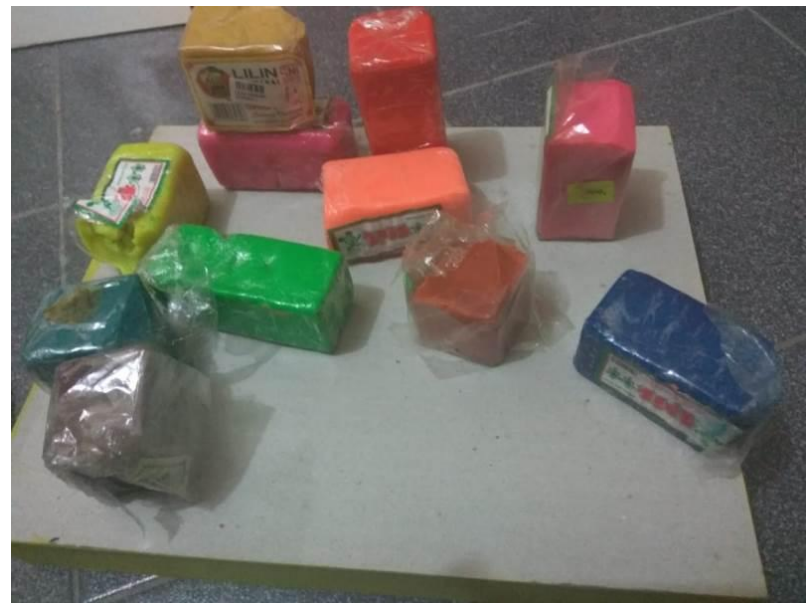

Gambar 11.

Foto plastisin

(foto: Asa, 2018)

Plastisin adalah mainan anak anak yang bersifat lunak dan merupakan benda padat yang dapat ditekan dan dibentuk sesuai keinginan. Plastisin dijadikan model atau gambaran purwarupa dalam proses mewujudkan karya seni lukis. Manfaat dari penggunaan model tersebut di antaranya dapat memberi terang gelap yang pas, kemudian memberi bentuk dan volume yang tak disengaja yang menimbulkan kesan artistik yang naif.

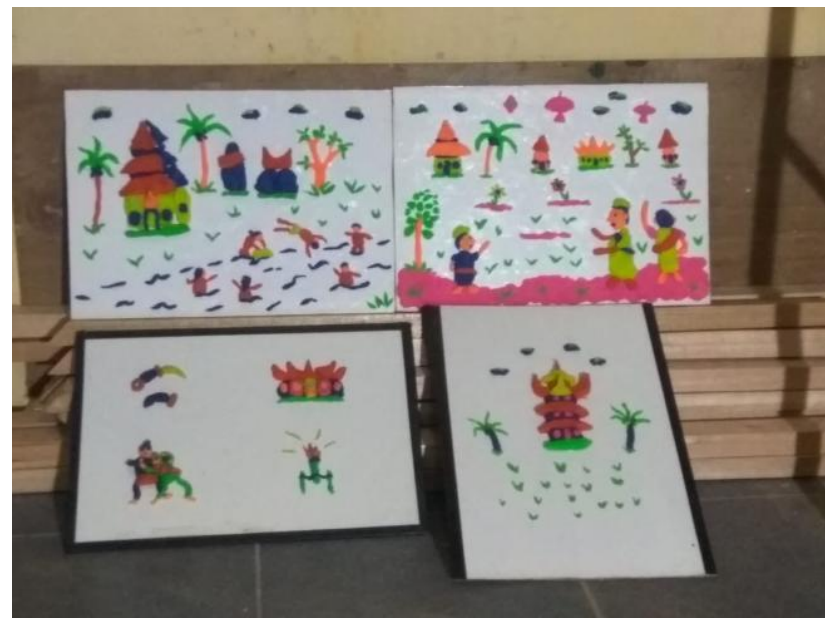

Gambar 12

Foto hasil eksperimen plastisin pada triplek

(foto: Asa, 2018)

\section{Perenungan}

Perenungan atau kontemplasi merupakan salah satu metode dalam penciptaan karya seni lukis. Perenungan dilakukan untuk menemukan sesuatu yang akan menjadi nilai dalam proses kreatif artistik pada lukisan yang akan diciptakan. Pengkarya berusaha melakukan perenungan untuk mendapatkan hal-hal yang baru untuk mempertajam rasa atau sensibilitas di dalam berolah seni, karena seni merupakan "ekspresi terencana" dari dalam diri pengkarya.

\section{2).Platisin}




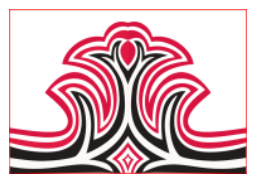

\section{HASIL DAN PEMBAHASAN}

1.Karya 1 "Mengaji"

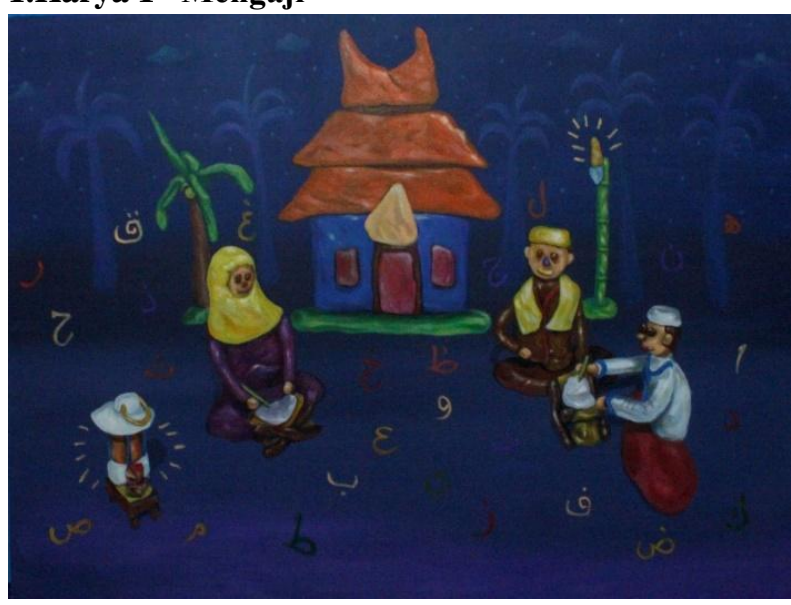

Gambar 13.

Ferdian Ondira Asa, 2018, “Mangaji”. 110 x 120. Akrilik pada kanvas,

(foto; Asa, 2018)

Karya ini dibuat berdasarkan pengamatan, wawancara, serta bentuk kepedulian penulis terhadap hilangnya kehidupan surau di zaman ini. Karya tersebut menjelaskan salah satu kehidupan surau, yakni mangaji. Mangaji (mengaji) merupakan salah satu ilmu dasar yang dapat dipelajari di surau. Kegiatan mangaji dilakukan oleh anak-anak hingga remaja. Dulunya, setiap sore semua anak-anak dan remaja akan pergi mengaji ke surau. Hal ini sudah menjadi tradisi di Minangkabau.

Plastisin diolah menjadi objek yang akan dilukis, dibentuk menjadi tiga orang, dua orang yang menjadi murid, satu orang menjadi guru ngaji. Kemudian, pada karya tersebut terlihat bangunan surau, lampu petromaks, huruf hijaiyah, pohon, dan suluah. Dibuat dengan warna gelap karena di Minangkabau belajar mengaji di surau waktunya adalah setelah sholat magrib.

Orang-orang belajar mengaji berada di luar surau maksudnya agar penikmat karya langsung mengetahui bahwa belajar mengaji dilaksanakan di surau. Mereka belajar mengaji ditemani lampu petromaks. Suluah berfungsi penerang jalan jika mereka hendak pulang ke rumah.

Jadi, melalui karya ini penulis beraspirasi untuk melestarikan kembali fungsi surau, yakni mangaji. Dengan mangaji, seseorang mampu memahami isi alquran dengan benar. Pedoman yang terdapat di dalam alquran dapat menjadi petunjuk dalam menjalani kehidupan. Kehidupan yang baik, berakhlak baik, dan sesuai ajaran agama Islam.

\section{Gorga Jurnal Seni Rupa \\ Volume 07 Nomor 02 \\ p-ISSN: 2301-5942 | e-ISSN: 2580-2380}

Persoalan yang dihadirkan kepada penikmat karya adalah persoalan bagaimana cara menghidupkan kembali kehidupan surau, khususnya di daerah Minangkabau. Penulis ingin mengajak masyarakat untuk memahami dan mengetahui bagaimana kehidupan surau pada zaman dulu. Saat kehidupan surau itu aktif, banyak kegiatan positif yang bisa diperoleh.

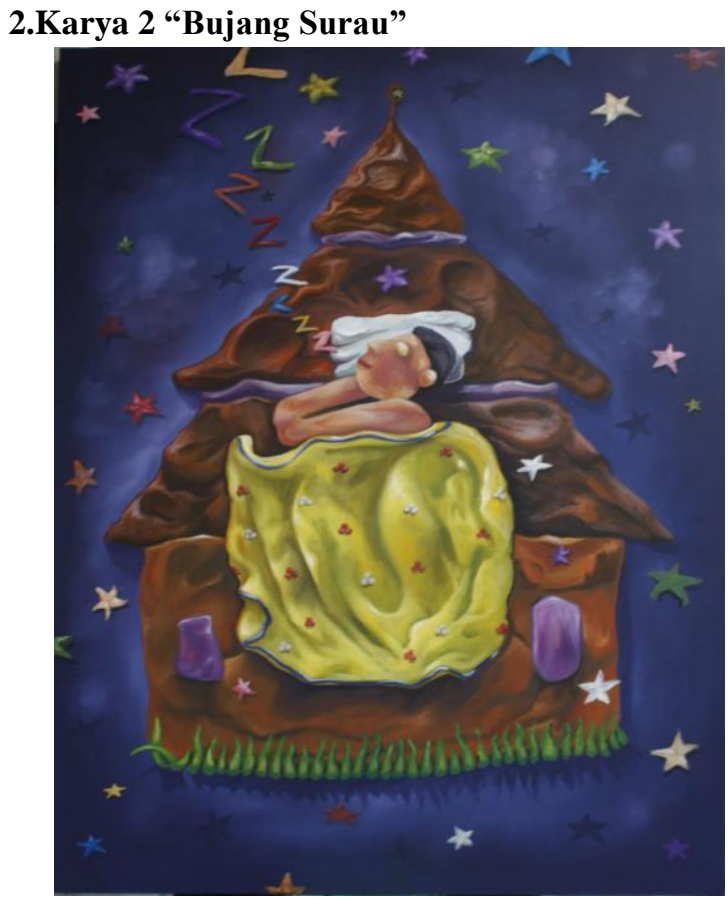

Gambar 14

Ferdian Ondira Asa, 2018, "Bujang Surau”. 145 x 110. Akrilik pada kanvas, (foto; Asa, 2018)

Karya tersebut juga menceritakan tentang kehidupan surau. Kehidupan surau yang diceritakan adalah budaya tidur di surau. Surau Minangkabau dengan figur orang yang sedang tidur. Pada bagian atas figur, terdapat bintang-bintang dan bunyi udara tidur. Background karya ini berwarna ungu tua. Maksud dari figure ini adalah seorang pemuda yang sedang tertidur di surau karena pemuda tersebut banyak menghabiskan waktu di surau untuk menuntut ilmu agama dan ilmu umum. Alasan dari Background warna ungu tua adalah pemuda tersebut tertidur di waktu malam hari sambil bermimpi. Maksud mimpi dan dihiasi bintang maknanya adalah pemuda tersebut bermimpi akan keindahan/kebaikan yang dihasilkan dari pendidikan di surau.

Bujang surau seorang remaja yang bermalam di surau, ini sudah menjadi budaya bagi anak laki laki yang di karenakan di rumah nya sendiri tidak ada kamar untuk tidur. Biasanya terjadi lantaran kakak atau adeknya sudah menikah dan mendapat kamar di 


\section{Gorga Jurnal Seni Rupa \\ Volume 07 Nomor 02 \\ p-ISSN: 2301-5942 | e-ISSN: 2580-2380}

rumah gadang sehingga anak remaja banyak yang tidur di surau.

Persoalan yang ingin dikemukakan oleh penulis adalah bagaimana mengembalikan ingatan penikmat karya terhadap fenomena yang memberikan manfaat kebersamaan, khususnya masyarakat Minangkabau. Indahnya jika waktu diisi dengan hal yang bermanfaat. Tentu akan membuahkan, hasil yang positif. Hal tersebut dapat dilihat dari fenomena yang terjadi dalam masyarakat. Bagaimanan jadinya jika seseorang tidak memiliki sikap peduli, empati, dan kepekaan yang tinggi. Contohnya, dalam bertetangga jika tidak saling toleransi tentu kehidupan bertetangga tidak akan rukun. Persoalan-persoalan tersebutlah yang menggelitik penulis untuk menciptakan karya lukis tentang kehidupan surau di Minangkabau. Selain ingin memberikan penjelasan tentang fungsi surau yang telah hilang, penulis juga ingin beraspirasi agar masyarakat Minangkabau mampu melestarikan surau sehingga dapat membentuk karakter pemuda-pemudi mereka menjadi lebih baik. Bukan menjadikan karakter yang menenggelamkan nilai-nilai luhur daerah.

\section{KESIMPULAN DAN SARAN}

\section{Kesimpulan}

Penciptaan karya lukis kehidupan surau sebagai inspirasi merupakan bentuk aspirasi dari penulis terhadap kehidupan surau pada saat ini. Melalui karya lukis yang digarap, penikmat karya diharapkan mampu mengetahui fungsi surau. Dulunya, surau dijadikan tempat perkumpulan pemuda-pemudi untuk menuntut ilmu agama, berkumpul untuk bediskusi, bermain, bahkan dijadikan tempat tidur bila malam datang. Anak laki-laki yang telah baligh dianjurkan tidur di surau karena mereka tidak memiliki kamar di rumah, Rumah Gadang. Rumah Gadang adalah rumah yang ditempati oleh orang tua mereka. Di Minangkabau, Rumah Gadang hanya boleh ditempati oleh anak perempuan saja.

Sekarang, kehidupan surau yang telah menjadi tradisi tersebut tidak dapat dirasakan, bahkan surau telah menjadi bangunan tua yang tidak difungsikan lagi. Akibatnya, pemuda-pemudi Minangkabau sekarang banyak memanfaatkan waktu dengan kegiatan yang tidak berguna. Contohnya, menggunakan gadget, berkumpul dengan teman di warung, serta melakukan kegiatan yang melanggar agama.

\section{Saran}

Karya yang hadir ini nantinya mampu memberikan kritikan dan pandangan terhadap pemimpin yang memiliki peranan seperti dijelaskan pada latar belakang sehingga apa yang mereka perbuat sadar dan lebih mengerti lagi akan peranan mereka sangat penting dalam masyarakat. Melalui karya ini diharapkan juga mampu memberikan motivasi terhadap seniman-seniman muda dalam berolah rasa untuk menciptakan karya terbaru

\section{DAFTAR RUJUKAN}

Azra, Azyumardi. 2017. Surau: Pendidikan Islam Tradisional dalam Transisi dan Modernisasi. Jakarta: Pusat Pengkajian Islam dan Masyarakat (PPIM) UIN Syarif Hidayatullah Jakarta.

Sony Kartika, Dharsono. 2016. Kreasi Artistik. Surakarta: LPKBN Citra Sains.

Gazalba, Sidi. 1994. Mesjid Pusat Ibadat dan Kebudayaan Islam. Jakarta: Al Husna Zikra.

\section{WEBSTOGRAFI}

http://www.harpersbazaar.co.id/articles/read/2/2017/3 471/Persembahan-Cinta-Seorang-RonaldApriyan

https://www.tembi.net/2017/06/03/squezee-land-citra kertas-remas-dalam-karya-lukis-ipan/

https://lukisanku.id/lukisan-ironi-minangkabau-kamalguci 